Research Article

\title{
Actuarial Modelling for Patients with Acute Lymphoblastic Leukaemia (ALL) based on CNSI Status
}

\author{
Gurprit Grover', Parmeet Kumar Vinit $^{2}$ \\ 1,2 Department of Statistics, University of Delhi, Delhi, India. \\ DOI: https://doi.org/10.24321/0019.5138.202136
}

I $\mathbf{N} \quad \mathbf{F} \mathbf{O}$

\section{Corresponding Author:}

Parmeet Kumar Vinit, Department of Statistics, University of Delhi, Delhi, India.

E-mail Id:

parmeet.vinit@gmail.com

Orcid Id:

https://orcid.org/0000-0002-1779-6522

How to cite this article:

Grover G, Vinit PK. Actuarial Modelling for Patients with Acute Lymphoblastic Leukaemia (ALL) based on CNS1 Status. J Commun Dis. 2021;53(3):23-32.

Date of Submission: 2021-06-03

Date of Acceptance: 2021-09-20

\author{
$\begin{array}{llllllll}\mathbf{A} & \mathbf{B} & \mathbf{S} & \mathbf{T} & \mathbf{R} & \mathbf{A} & \mathbf{C} & \mathbf{T}\end{array}$
}

Introduction: Worldwide, Acute Lymphoblastic Leukaemia (ALL) is the most frequent cancer in children. One of the major clinical challenges is adequate diagnosis and treatment of Central Nervous System (CNS) involvement in this disease. CNS relapse has been a barrier to the successful treatment of ALL for many years. Recent studies have shown encouraging results in the survival of these patients for a long time. However, their long-term survival depends upon the cost of therapy toxicity and financial distress. The primitive aim of the paper is to propose a yearly insurance plan to assist these patients financially during the diagnosis period.

Method: Based on the CNS status 110 patients are categorised to estimate their long-term survival. Survival times of CNS1 status and for all the patients cumulatively are estimated by Kaplan-Meier and Cox$\mathrm{PH}$ model in presence of the prognostic factors. The survival estimates are used to estimate the premium cost. The premium cost is estimated using a deterministic model which is advantageous for the patient and serviceable for the insurance provider.

Result: Both the methods Kaplan-Meier and Cox- $\mathrm{PH}$ gave higher survival estimates for ALL patients cumulatively as compared to CNS1. Survival estimate from Cox-PH is 0.998 and 0.997 of first year of follow-up for patients taken cumulatively and in CNS1 respectively. For the fifth year the survival estimates are 0.802 and 0.783 respectively. The estimated premium cost for a 100 rupees of sum insured is rupees 4.7 for the first year and rupees 26.69 for the fifth year for patients taken cumulatively. Same for CNS1, it is rupees 6.24 and 29.42 .

Conclusion: Cox-PH model for estimating the survival is recommended since it includes the prognostic factors. The insurance plan suggests to opt for the premium as early as possibly since it costs less and increases later.

Keywords: ALL, CNS, Insurance, Premium, Finance 


\section{Introduction}

Acute Lymphoblastic Leukaemia (ALL) is a type of blood cancer commonly in young children and it affects adults as well. It is an acquired genetic disease that is caused by a combination of environmental factors and mutations in multiple genes. ${ }^{1}$ The word "acute" in acute lymphocytic leukaemia comes from the fact that the disease progresses rapidly and creates immature blood cells, rather than mature ones. The word "lymphocytic" in acute lymphocytic leukaemia refers to the white blood cells called lymphocytes, which are responsible for ALL. Based on a medical procedure called Lumbar Puncture (LP) the spread of leukaemia cells to the Cerebral Spinal Fluid (CSF) is determined. Based on the blood cell count in the CSF an LP is classified as traumatic LP (TLP) or atraumatic LP (ATLP). An individual is considered to be ATLP if the count of RBCs per microliter of CSF is less than 10 else TLP. ${ }^{2} A$ healthy individual's CSF is free from red blood cells (RBCs).

At the beginning of the 20th century, the use of chemotherapy advanced for the treatment of the various types of cancers and ALL as well. ${ }^{3}$ Approximately $70 \%$ of children with ALL can be cured with contemporary forms of chemotherapy. ${ }^{4,5} \mathrm{~A}$ positive relationship was found between systemic exposure to chemotherapy and anticancer effects. ${ }^{6}$

Nowadays ALL is curable to a great extend with proper and continuous diagnosis in the early stages. Central nervous system (CNS) relapse has been an obstacle to uniformly successful treatment of childhood ALL for many years. The 5-year cumulative risk of an isolated CNS relapse among all 165 patients was $1.2 \%$, whereas that of any CNS relapse was $3.2 \%(0.4 \%$ to $6.0 \%)$. The probability of surviving for 5 years without an adverse event of any type was $80.2 \% \pm$ 9.2\% (SE). Early intensification of intrathecal chemotherapy will reduce the risk of CNS relapse to a very low level in children with ALL, securing a higher event-free survival rate overall. ${ }^{4}$ Approximately $70 \%$ of children with ALL can be cured with contemporary forms of chemotherapy. Lowering the incidence of CNS relapse would be one of the approaches to improve further, which in most studies ranges from $5 \%$ to $11 \% .{ }^{5}$ Any number of leukemic cells in the CSF identifies patients who may benefit from intensified intrathecal chemotherapy, which effectively prevents CNS relapse in cases of intermediate or high-risk ALL. ${ }^{7}$

In general, the studies show that survival in ALL is more than $60 \%$ but ranges from $45 \%$ to $81 \%$ and event-free survival from $41 \%$ to $70 \%{ }^{8}$ The cure rate in the treatment of ALL has increased rapidly, $80 \%$ of children and $40 \%$ of adults are curable ${ }^{9}$, the overall five-year survival is 80 to $86 \%{ }^{10}$

The article ${ }^{11}$ suggests the immediate need for an insurance policy based on the TLP and ATLP for ALL patients. Here, an insurance policy based on CNS status is suggested for ALL patients.

\section{Materials and Methods}

This retrospective study is based on the data set of 110 ALL patients obtained from AlIMS, Delhi. ${ }^{12}$ For the preliminary study, survival analysis is performed on the duration of follow up i.e., time from diagnosis of ALL to the time of the last contact is taken as the main study variable. Apart from this other demographic and prognostic factors considered are age, sex, BMI, bulky (0 - No, 1 Yes): bulky extramedullary disease, DOS (mean duration of symptoms in which patients experiences symptoms of ALL), delays (in days), or interventions in chemotherapy due to toxicity such as neutropenia or severe infections, Pre TLC: presenting total leukocyte count (per microliter), IPT: immunophenotype (B lymphocytes, T lymphocytes), blast, platelets: platelets count at the time of last lumbar puncture (per microliter), days of LP: number of days since the previous LP, steroid + leunase ( 0 - none, 1 - steroid only, 2 - both), protocol (1 - SBFM: Standard Berlin-Frankfurt Munster chemotherapy, 2 - ABFM: Augmented BerlinFrankfurt Munster chemotherapy), therapy omissions (0 no, 1 - yes), HD-MTX (0 - no, 1 - yes) High Dose Methotrexate, follow up (1 - no relapse, 2 - CNS relapse, 3 - bone marrow relapse, 4 - combined relapse) and CNS status is defined ${ }^{13}$ as follows:

CNS1 - LP atraumatic ( $<10 \mathrm{RBC}$ s per microliter) and $<5$ WBCs per microliter with no identifiable leukemic blast cells (LBC) after cytocentrifugation, CNS2 - LP atraumatic ( $<10$ RBCs per microliter) and $<5$ WBCs per microliter with $L B C$ after cytocentrifugation, CNS3 - LP atraumatic ( $<10$ RBCs per microliter) and $\geq 5 \mathrm{WBCs}$ with $\mathrm{LBC}$ after cytocentrifugation, CNS4 - Negative TLP- LP traumatic ( $\geq 10$ RBCs) with no LBC after cytocentrifugation, CNS5 -Positive TLP - LP traumatic ( $\geq 10 \mathrm{RBCs}$ ) with LBC after cytocentrifugation, as described in Figure 1.

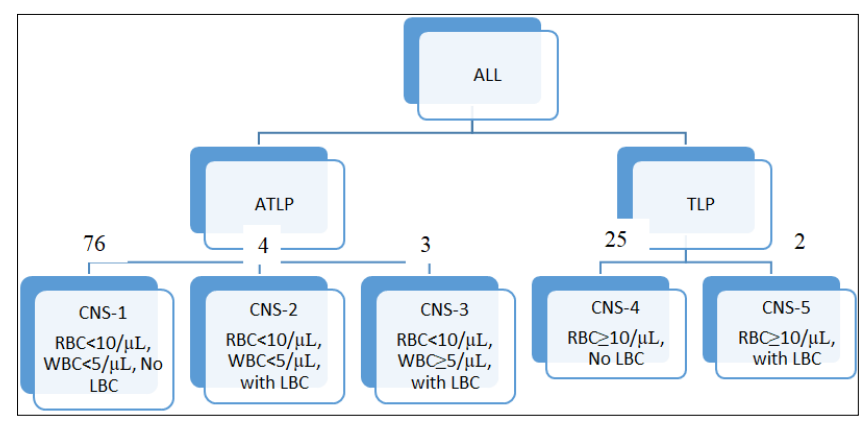

Figure I.Classification based on CNS Status

\section{Methods}

Let $u_{i}(t)$ be the hazard rate of the patient in the $j^{\text {th }}$ CNS status. The Cox-PH model is used to get the hazard rate for all the CNS status, in the presence of prognostic factors. The purpose of this model is to evaluate simultaneously the effect of several prognostic factors on the survival of 
ALL patients under different CNS statuses $(j=1,2 \ldots 5)$.

$\mu_{j}(t)=\mu_{0}(t) \cdot \exp \left(b_{1} x_{1}+b_{2} x_{2}+\ldots+b_{p} x_{p}\right)$

Where, $x_{i}$ is the $i^{i \text { th }}$ prognostic factor, with coefficient $b_{i}$ and $\mu_{0}(t)$ is baseline hazard rate.

Further, the probability of surviving one year $(t=1)$ with $\mu_{\mathrm{i}}(t)$ hazard rate is given by:

$p_{x}^{j}=\exp \left\{-\int_{0}^{1} \mu_{j}(t) d x\right\}$

These probabilities of deaths can be used in the decrement model, to calculate death probabilities ${ }^{14}$ in the presence of prognostic factors.

\section{Premium Model}

The death probabilities of ALL patients $\left(q_{x}^{(j)}\right)$ is used to calculate insurance premium for the given time period $(t=1)$. Models for insurance are designed to reduce the financial impact of untimely death. Insurance systems are established to reduce the adverse financial impact of some type of random event, here death is the primary event. We have considered the model for one year of insurance. Value of payable insurance premium $\left(\bar{A}_{x, i}^{1}\right)^{15}$ for the ALL patient, with the rate of interest $i$ is calculated as:

$\bar{A}_{x, i}^{1}=q_{x}^{(j)} \cdot v+p_{x}^{(j)} \cdot q_{x+1}^{(j)} \cdot v^{2}$

Where, $v=(1+i)^{-1}$ is the discount factor used to calculate the value of unit currency after one year based on compound interest with the rate of interest $\mathrm{i}$.

\section{Results}

Table 1 describes the facets of all the 110 cases of ALL patients understudy and 76 (69.1\%) were under CNS 1 category. Out of these $85(77.3 \%)$ were males and $63(82.9 \%)$ of them were under CNS 1 category. Out of a total of 25 females, 13 (17.1\%) came under CNS 1 category. Phenotyping (IPT) was for B-cells for 86 (78.2\%). Few other main features were $30.1 \%$ of patients have discontinuous therapy, $70 \%$ of the patients were followed by ABFM protocol, radiation therapy has opted for $81.8 \%$, only $4.5 \%$ were given High Dose Methotrexate (HD_MTX) and 79\% were alive. For the numeric predictors, the median age was 18 , mean BMI was 18.2 and average follow-up duration was 25 months.

The various prognostic factors affecting survival are explained in Table 2. Few results that can be drawn from this table are as follows: overall one unit increase in age affects the hazard by 0.97 times whereas BMI increases the hazard by 1.112 times. Excess of long DOS of 1 unit increases the hazard by 1.013 times and also it is significant at a $5 \%$ level of significance.

Therapy omission is a significant factor and one-time skipping leads to increases in 2.7 times of the hazard.

Table I.Description of the Predictors for All the Cases under Study (a) Categorical Predictors, (b) Numeric Predictors

\begin{tabular}{|c|c|c|c|}
\hline \multicolumn{4}{|c|}{ (a) Categorical predictors } \\
\hline & & All Cases & CNS 1 \\
\hline \multirow{2}{*}{ Sex } & Male & $85(77.3 \%)$ & $63(82.9 \%)$ \\
\hline & Female & $25(22.7 \%)$ & $13(17.1 \%)$ \\
\hline \multirow{2}{*}{ IPT } & B & $86(78.2 \%)$ & $58(76.3 \%)$ \\
\hline & $\mathrm{T}$ & $24(21.8 \%)$ & $18(23.7 \%)$ \\
\hline \multirow{5}{*}{ CNS_status } & CNS1 & $76(69.1 \%)$ & \\
\hline & CNS2 & $4(3.6 \%)$ & \\
\hline & CNS3 & $3(2.7 \%)$ & \\
\hline & Neg_CNS & $25(22.7 \%)$ & \\
\hline & Pos_CNS & $2(1.8 \%)$ & \\
\hline \multirow{2}{*}{ Bulky } & No & $80(72.7 \%)$ & 55 (72.4\%) \\
\hline & Yes & $30(27.3 \%)$ & $21(27.6 \%)$ \\
\hline \multirow{2}{*}{ Blast } & No & $63(57.3 \%)$ & 45 (59.2\%) \\
\hline & Yes & $47(42.7 \%)$ & $31(40.8 \%)$ \\
\hline \multirow{3}{*}{ S_L } & None & $25(22.7 \%)$ & $17(22.4 \%)$ \\
\hline & Steroid & 45 (40.9\%) & $32(42.1 \%)$ \\
\hline & Both & $40(36.4 \%)$ & $27(35.5 \%)$ \\
\hline \multirow{2}{*}{ Protocol } & SBFM & $33(30 \%)$ & $22(28.9 \%)$ \\
\hline & ABFM & 77 (70\%) & 54 (71.1\%) \\
\hline
\end{tabular}




\begin{tabular}{|c|c|c|c|}
\hline \multirow{2}{*}{ Therapy_omissions } & No & 76 (69.1\%) & 49 (64.5\%) \\
\hline & Yes & 34 (30.9\%) & 27 (35.5\%) \\
\hline \multirow{2}{*}{ RT } & No & $17(15.5 \%)$ & $11(14.5 \%)$ \\
\hline & Yes & $90(81.8 \%)$ & $65(85.5 \%)$ \\
\hline \multirow{2}{*}{ HD_MTX } & No & 105 (95.5\%) & $72(94.7 \%)$ \\
\hline & Yes & $5(4.5 \%)$ & $4(5.3 \%)$ \\
\hline \multirow{4}{*}{ Follow-up } & No relapse & $86(78.2 \%)$ & $60(78.9 \%)$ \\
\hline & CNS1 & $19(17.3 \%)$ & $13(17.1 \%)$ \\
\hline & Bone marrow & $4(3.6 \%)$ & $4(5.3 \%)$ \\
\hline & Combined & $1(0.9 \%)$ & \\
\hline \multirow{2}{*}{ Alive } & No & $22(20 \%)$ & $16(21.1 \%)$ \\
\hline & Yes & $87(79.1 \%)$ & $60(78.9 \%)$ \\
\hline \multicolumn{4}{|c|}{ (b) Numeric predictors } \\
\hline & & Mean & Median \\
\hline \multicolumn{2}{|c|}{ Age } & 19.4 & 18.0 \\
\hline \multicolumn{2}{|c|}{ BMI } & 18.2 & 17.1 \\
\hline \multicolumn{2}{|c|}{ DOS } & 59.2 & 45.0 \\
\hline \multicolumn{2}{|c|}{ Delay } & 12.7 & 6.5 \\
\hline \multicolumn{2}{|c|}{ Pre_TLC } & 67355.6 & 22730.0 \\
\hline \multicolumn{2}{|c|}{ Platelet } & 64.5 & 30.0 \\
\hline \multicolumn{2}{|c|}{ Day_of_LP } & 6.5 & 5.5 \\
\hline \multicolumn{2}{|c|}{ Follow-up_duration } & 25.8 & 15.5 \\
\hline
\end{tabular}

Table 2.Cox-PH Regression on Prognostic Factors for ALL Patients

\begin{tabular}{|c|c|c|c|c|c|c|}
\hline \multirow{2}{*}{ Variables } & \multirow{2}{*}{ B } & \multirow{2}{*}{ SE } & \multirow{2}{*}{ Sig. } & \multirow{2}{*}{ HR } & \multicolumn{2}{|c|}{ 95.0\% Cl for $\operatorname{Exp}(\mathrm{B})$} \\
\hline & & & & & Lower & Upper \\
\hline Age & -0.03 & 0.033 & 0.363 & 0.97 & 0.909 & 1.036 \\
\hline Sex & -0.265 & 0.638 & 0.678 & 0.767 & 0.22 & 2.681 \\
\hline BMI & 0.106 & 0.073 & 0.145 & 1.112 & 0.964 & 1.282 \\
\hline Bulky & -0.107 & 0.657 & 0.871 & 0.899 & 0.248 & 3.257 \\
\hline DOS & 0.013 & 0.006 & 0.038 & 1.013 & 1.001 & 1.025 \\
\hline Delay & -0.006 & 0.027 & 0.827 & 0.994 & 0.943 & 1.048 \\
\hline Pre_TLC & 0 & 0 & 0.545 & 1 & 1 & 1 \\
\hline IPT & -2.411 & 0.979 & 0.014 & 0.09 & 0.013 & 0.611 \\
\hline Blast & -1.56 & 0.782 & 0.046 & 0.21 & 0.045 & 0.973 \\
\hline Platelet & 0.003 & 0.003 & 0.441 & 1.003 & 0.996 & 1.009 \\
\hline Day_of_LP & -0.068 & 0.055 & 0.216 & 0.934 & 0.838 & 1.041 \\
\hline S_L & 0.079 & 0.467 & 0.865 & 1.083 & 0.433 & 2.706 \\
\hline Protocol & 1.166 & 0.693 & 0.092 & 3.208 & 0.826 & 12.464 \\
\hline Therapy_omissions & 1.026 & 0.54 & 0.057 & 2.791 & 0.968 & 8.042 \\
\hline RT & -1.82 & 0.778 & 0.019 & 0.162 & 0.035 & 0.744 \\
\hline HD_MTX & -13.891 & 503.199 & 0.978 & 0 & 0 & . \\
\hline
\end{tabular}




\section{Kaplan Meier Survival Estimates}

The survival for all the cases under study is estimated based on the follow-up duration. At the time when the first event occurs the survival estimated is very high (0.991). By the time the 5 th event occurs survival estimate declines by $4 \%$. After one year the survival estimates fall by $14 \%(0.857)$ and $36 \%(0.638)$ at the end of five-year period (Table 3).

Figure 2 shows the Kaplan Meier survival plot for ALL patients. In the beginning, the survival estimates decrease and slow down from 0.8 to 0.75 during 20th to 55th month.
Again, it declines drastically. The plot clearly explains that the long-term survival is more than $60 \%$.

Now, the cases of all the ALL patients are categorised based on the CNS status. In Table 4 the survival for all the cases under study is estimated based on the follow-up duration for the cases in CNS 1 category. At the time when the first event occurs the survival estimated is very high (0.991). By the time the 5 th event occurs survival estimate declines by $6 \%$. After, the period of a year the survival estimates fall by $15 \%(0.857)$ and $35 \%(0.638)$ at the end of five-year period.

Table 3.Kaplan Meier Estimates for ALL Patients

\begin{tabular}{|c|c|c|c|c|}
\hline $\begin{array}{c}\text { Time } \\
\text { (Months) }\end{array}$ & $\begin{array}{c}\text { Cumulative proportion } \\
\text { surviving at the time }\end{array}$ & Std. error & N of cumulative events & N of remaining cases \\
\hline 1 & 0.991 & 0.009 & 1 & 109 \\
\hline 2 & 0.972 & 0.016 & 3 & 104 \\
\hline 3 & 0.963 & 0.018 & 4 & 100 \\
\hline 4 & 0.953 & 0.021 & 5 & 95 \\
\hline 6 & 0.931 & 0.025 & 7 & 86 \\
\hline 7 & 0.92 & 0.027 & 8 & 85 \\
\hline 11 & 0.896 & 0.031 & 10 & 74 \\
\hline 12 & 0.857 & 0.037 & 13 & 67 \\
\hline 14 & 0.844 & 0.039 & 14 & 61 \\
\hline 19 & 0.827 & 0.042 & 15 & 50 \\
\hline 21 & 0.81 & 0.044 & 16 & 48 \\
\hline 25 & 0.791 & 0.047 & 17 & 41 \\
\hline 35 & 0.765 & 0.052 & 18 & 29 \\
\hline 55 & 0.684 & 0.071 & 20 & 17 \\
\hline 59 & 0.638 & 0.08 & 21 & 14 \\
\hline 65 & 0.575 & 0.094 & 22 & 9 \\
\hline
\end{tabular}

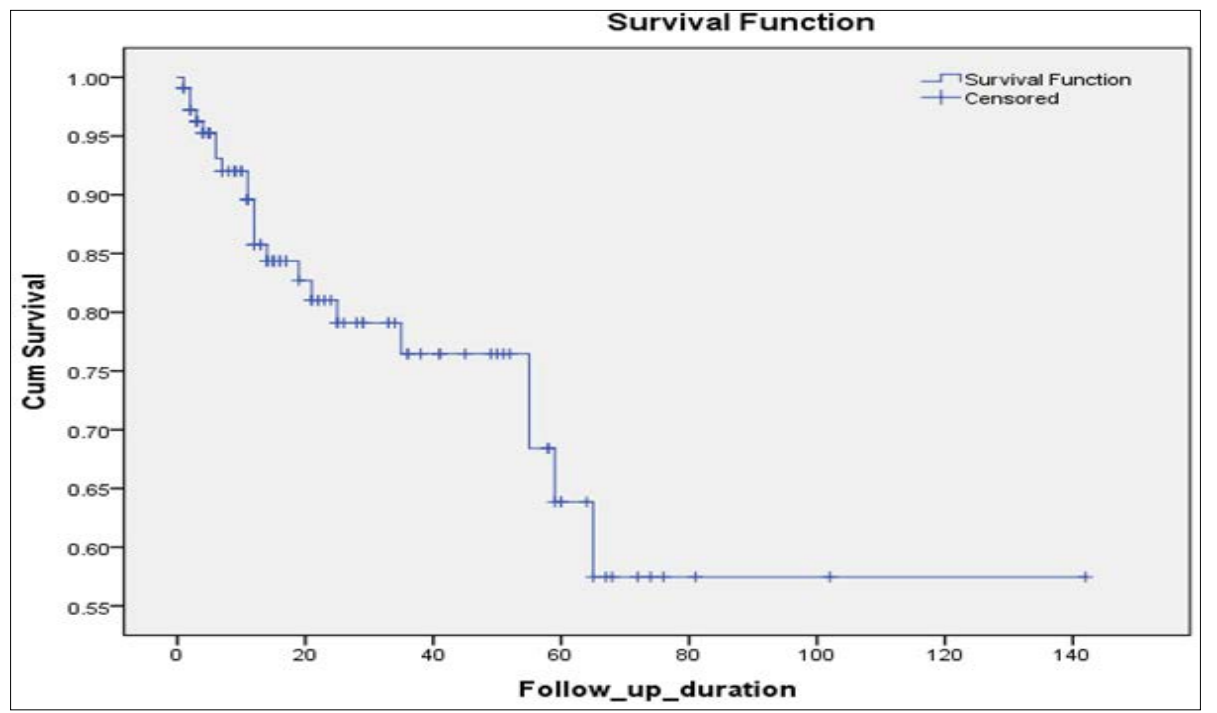

Figure 2.Kaplan Meier Survival Plot for the ALL Patients 
Table 4.Kaplan Meier Estimates for ALL Patients of CNS I Category

\begin{tabular}{|c|c|c|c|c|}
\hline Time (Months) & $\begin{array}{c}\text { Cumulative proportion surviving at } \\
\text { the time }\end{array}$ & Std. error & $\begin{array}{c}\text { N of cumulative } \\
\text { events }\end{array}$ & $\begin{array}{c}\text { N of remaining } \\
\text { cases }\end{array}$ \\
\hline 1 & 0.987 & 0.013 & 1 & 75 \\
\hline 3 & 0.973 & 0.019 & 2 & 70 \\
\hline 4 & 0.958 & 0.024 & 3 & 65 \\
\hline 6 & 0.926 & 0.032 & 5 & 58 \\
\hline 7 & 0.91 & 0.035 & 6 & 57 \\
\hline 11 & 0.874 & 0.042 & 8 & 48 \\
\hline 12 & 0.835 & 0.048 & 10 & 43 \\
\hline 19 & 0.809 & 0.053 & 11 & 31 \\
\hline 21 & 0.782 & 0.058 & 12 & 29 \\
\hline 35 & 0.746 & 0.065 & 13 & 21 \\
\hline 55 & 0.697 & 0.078 & 14 & 14 \\
\hline 59 & 0.643 & 0.088 & 15 & 12 \\
\hline 65 & 0.572 & 0.103 & 16 & 8 \\
\hline
\end{tabular}

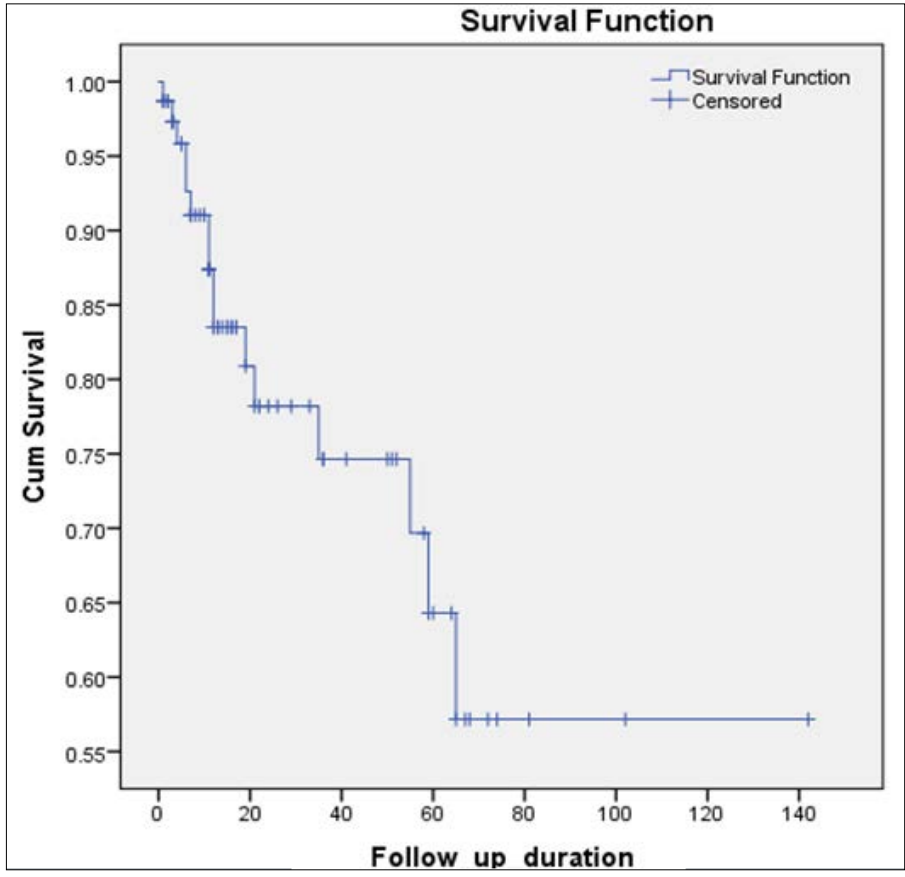

Figure 3.Kaplan Meier Survival Plot for the ALL Patients of CNS I Category

The Kaplan Meier survival plot for the ALL patients of the CNS 1 category is shown in Figure 3. The line for cumulative survival comes down very friskily in the first 12 months and slows down a little. Over the period of 5 years, the long-term survival is suggested by the plot is close to $65 \%$.

\section{Survival Estimates of Cox-PH Regression in Presence of the Prognostic Factors}

Till now the survival was estimated only based on follow-up duration. Now, the survival estimates are obtained using Cox-PH regression. This statistical technique can be used for survival-time (time-to-event) outcomes on one or more prognostic factors. Also, Cox-PH is a semi-parametric method that gives a better representation of real-life situation as compared to Kaplan-Meier, which is non-parametric. Table 5 estimates the survival for ALL patients at the mean of the covariates using Cox-PH regression. The survival estimate is 0.998 when the first event occurs in presence of prognostic factors. When the 5 th event occurs, the survival estimates decline by $1 \%$. At the end of one year, the survival estimate drops by $5 \%$ and later $20 \%$ by the end of 5 years. 
Table 5.Survival Estimates of ALL Patients in Presence of Prognostic Factors

\begin{tabular}{|c|c|c|c|c|}
\hline Time & Baseline cum hazard & Survival at mean of covariates & SE & Cum hazard \\
\hline 1 & 0.015 & 0.998 & 0.044 & 0.002 \\
\hline 2 & 0.032 & 0.996 & 0.092 & 0.004 \\
\hline 3 & 0.049 & 0.994 & 0.141 & 0.006 \\
\hline 4 & 0.078 & 0.99 & 0.223 & 0.01 \\
\hline 6 & 0.144 & 0.982 & 0.405 & 0.018 \\
\hline 7 & 0.179 & 0.978 & 0.502 & 0.022 \\
\hline 11 & 0.255 & 0.969 & 0.705 & 0.032 \\
\hline 12 & 0.385 & 0.953 & 1.043 & 0.048 \\
\hline 14 & 0.437 & 0.947 & 1.174 & 0.054 \\
\hline 19 & 0.505 & 0.939 & 1.34 & 0.063 \\
\hline 21 & 0.584 & 0.93 & 1.531 & 0.073 \\
\hline 25 & 0.686 & 0.918 & 1.771 & 0.085 \\
\hline 35 & 0.82 & 0.903 & 2.081 & 0.102 \\
\hline 55 & 1.353 & 0.845 & 3.061 & 0.168 \\
\hline 59 & 1.771 & 0.802 & 3.687 & 0.22 \\
\hline 65 & 2.659 & 0.719 & 5.112 & 0.331 \\
\hline
\end{tabular}

Figure 4 shows the plot of survival function at the mean of covariates. At the beginning cumulative survival decreases stepwise slowly around 25 months and then becomes gradual till 55 months. The long-term survival is around $80 \%$ as suggested by the cumulative survival plot in presence of the predictors.

Table 6 estimates the survival for ALL patients of CNS 1 category at the mean of the covariates using $\mathrm{Cox}-\mathrm{PH}$ regression. The survival estimate is 0.997 when the first event occurs in presence of prognostic factors. When the
5 th event occurs, survival estimate declines by $2 \%$. At the end of one year, the survival estimate drops by $6 \%$ and later $21 \%$ by the end of 5 years.

Figure 5 shows the plot of survival function at the mean of covariates. At the beginning cumulative survival decreases stepwise slowly around 20 months and then becomes gradual till 55 months. The long-term survival is more than $75 \%$ as suggested by the cumulative survival plot in presence of the predictors.

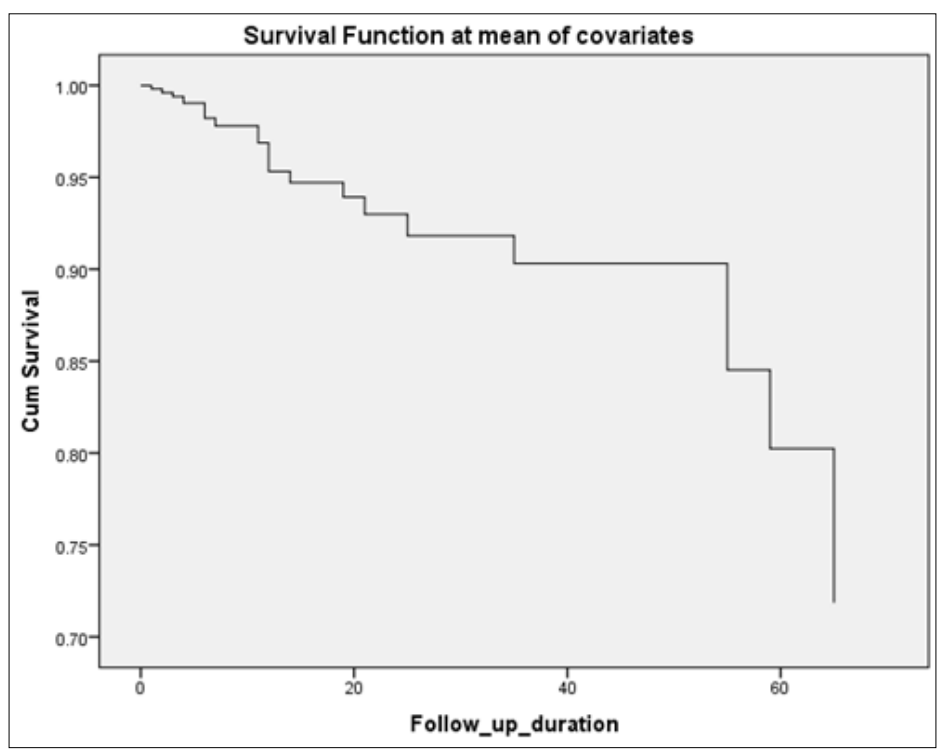

Figure 4.Survival Estimates of ALL Patients in Presence of Prognostic Factors 
Table 6.Survival Estimates of ALL Patients of CNS I Category in Presence of Prognostic Factors

\begin{tabular}{|c|c|c|c|c|}
\hline Time (Months) & Baseline cum hazard & $\begin{array}{c}\text { Survival at mean of } \\
\text { covariates }\end{array}$ & Sum hazard \\
\hline 1 & 0.008 & 0.997 & 0.111 & 0.003 \\
\hline 3 & 0.018 & 0.994 & 0.236 & 0.006 \\
\hline 4 & 0.035 & 0.989 & 0.476 & 0.011 \\
\hline 6 & 0.074 & 0.976 & 0.982 & 0.024 \\
\hline 7 & 0.095 & 0.97 & 1.246 & 0.031 \\
\hline 11 & 0.141 & 0.955 & 2.463 & 0.046 \\
\hline 12 & 0.195 & 0.938 & 2.923 & 0.076 \\
\hline 19 & 0.235 & 0.927 & 3.432 & 0.092 \\
\hline 21 & 0.282 & 0.912 & 4.25 & 0.118 \\
\hline 35 & 0.362 & 0.889 & 5.828 & 0.17 \\
\hline 55 & 0.521 & 0.844 & 7.242 & 0.245 \\
\hline 59 & 0.752 & 0.783 & 11.044 & 0.433 \\
\hline
\end{tabular}

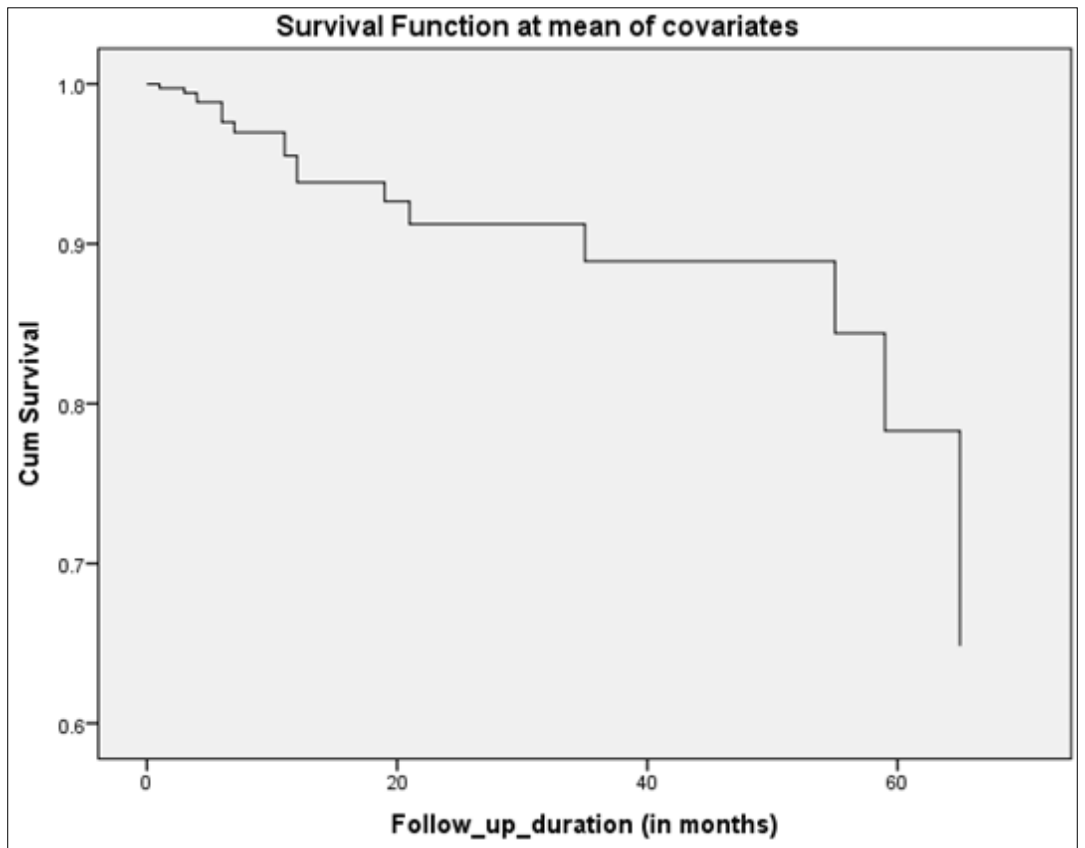

Figure 5.Survival Estimates of ALL Patients of CNS I Category in Presence of Prognostic Factors

\section{Calculation of Premium Cost}

The survival estimates of $\mathrm{Cox}-\mathrm{PH}$ regression are further utilised for the estimation of the premium cost. Table 7 shows the cost of the premium for all the ALL patients and of the CNS 1 category. It gives the estimated cost of the premium to be paid for a sum of rupees hundred ensured by the insurer. In the first year of follow-up, the estimated premium cost is very low i.e. Rs. 4.7 for all the ALL patients, whereas in the second year the cost increases by $134 \%$ to Rs. 11.02. Slowly the cost increases to 17.93 for the 5 th year and booms by $54 \%$ to Rs. 41.07 for the 6 th year.

Patients falling under CNS 1 category need to pay Rs 6.24 for ensuring the sum of Rs 100 in the first year. Further, in the very next year, the estimated premium cost increases by $125 \%$ to Rs. 14.01 . Gradually it increases to Rs. 29.42 for the 5 th year and again increases by $62 \%$ to Rs. 47.77 .

Figure 6 shows the comparison of premium cost (primaryaxis) and survival estimates (secondary-axis) for all the ALL patients and CNS1 category. The increasing trend of premium cost followed as the survival estimates decrease. 
Table 7.Cost of Premium for All the ALL Patients and of CNS I Category

\begin{tabular}{|c|c|c|c|c|c|c|}
\hline \multirow{2}{*}{ Year } & \multicolumn{3}{|c|}{ All patients } & \multicolumn{3}{c|}{ CNS1 } \\
\cline { 2 - 7 } & Survival & Premium (Rs) & Change (\%) & Survival & Premium (Rs) & Change (\%) \\
\hline 1 & 0.998 & 4.70 & - & 0.997 & 6.24 & - \\
\hline 2 & 0.953 & 11.02 & 134.24 & 0.938 & 14.01 & 124.72 \\
\hline 3 & 0.930 & 15.53 & 40.96 & 0.912 & 18.36 & 31.01 \\
\hline 4 & 0.903 & 17.93 & 15.42 & 0.889 & 20.37 & 10.95 \\
\hline 5 & 0.903 & 26.69 & 48.89 & 0.889 & 29.42 & 44.47 \\
\hline 6 & 0.802 & 41.07 & 53.86 & 0.783 & 47.77 & 62.33 \\
\hline 7 & 0.719 & - & - & 0.648 & - & - \\
\hline
\end{tabular}

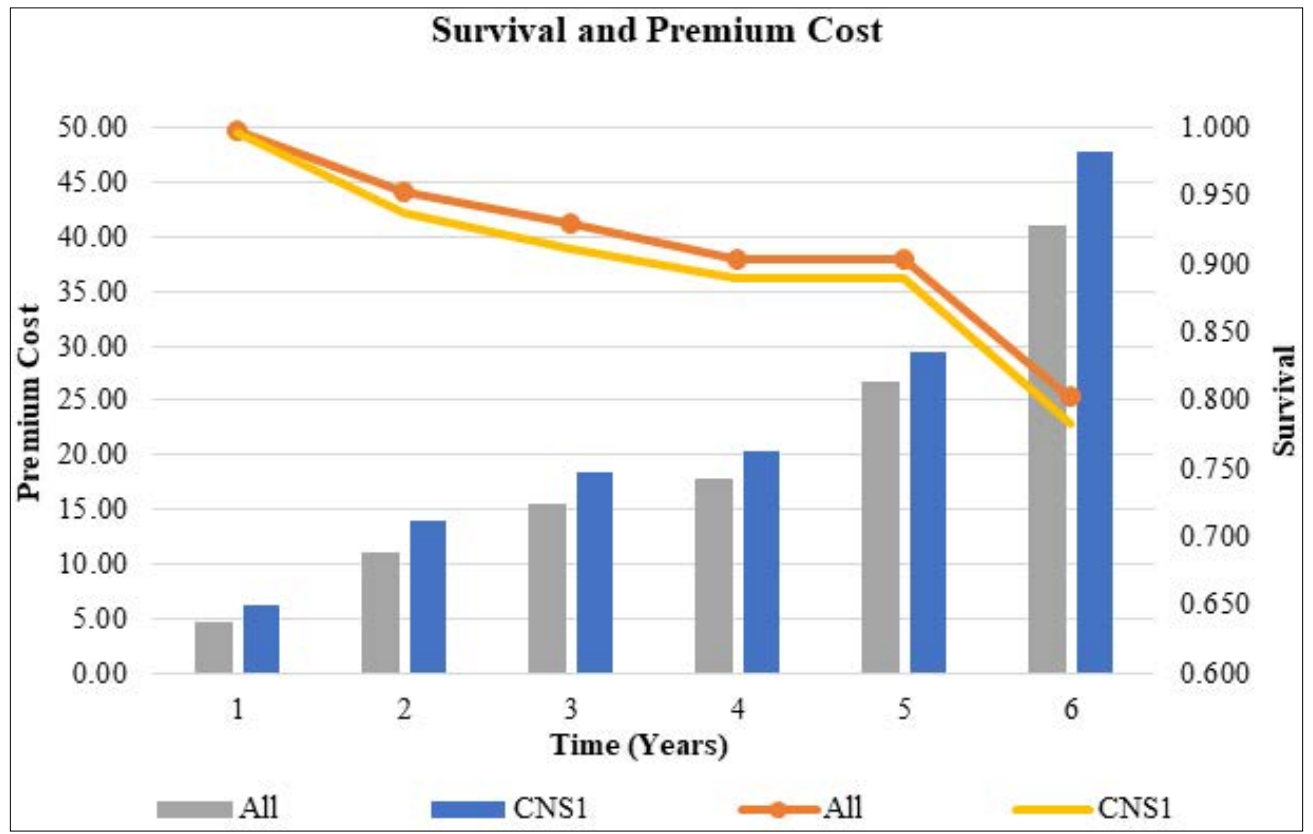

Figure 6.Comparison of Premium Cost (Primary-Axis) and Survival Estimates (Secondary-Axis) for All the ALL Patients and of CNSI Category

\section{Conclusion}

The cumulative survival for all the patients of ALL cases and in the CNS 1 category is estimated using two methods. The first was only based on follow-up duration using Kaplan Meier and the other was Cox-PH regression which considered all the prognostic factors for estimating the survival. As we compare the two methods, the latter gives more realistic results. Here, the survival estimates obtained in the presence of prognostic factors are very high i.e., above $75 \%$. These higher survival chances can be taken into account and can be considered for introducing and implement an insurance plan. It will be beneficial for the patient and people involved during the diagnosis and also workable for the insurer.

The suggested insurance plan provides a sum of Rs 100 insured against the premium of Rs 4.7 for all the patients and Rs 6.24 for the patients under the CNS 1 category.
The survival estimates decline adversely in the very next year and so is the premium cost i.e., $134 \%$ and $125 \%$ respectively. Further, during the long-term survival of 5 years, the premium cost does not increase very much but for the 6 th year, it increases by $54 \%$ and $62 \%$ respectively. It is suggested to opt for the insurance in the very first year of the follow-up to avoid payment of higher premiums.

The aim and strength of the study is to incorporate the prognostic factors affecting the survival in the patients and hence the cost of insurance. The study is limited to a particular region i.e., Delhi and also the number of cases. If a greater number of cases are observed then it will be possible to study the other categories of CNS. Also, the study does not involve the unavoidable charges that exist in the insurance handling i.e., the taxes, compensation to manpower exercised, etc.

Source of Funding: None 


\section{Conflict of Interest: None}

\section{References}

1. Bhutani M, Kochupillai V, Bakhshi S. Childhood acute Iymphoblastic leukemia: Indian experience. Ind J Med Ped Onco. 2004;25(2). [Google Scholar]

2. Howard SC, Gajjar AJ, Cheng C, Kritchevsky SB, Somes GW, Harrison PL, Ribeiro RC, Rivera GK, Rubnitz JE, Sandlund JT, de Armendi AJ, Razzouk BI, Pui CH. Risk factors for traumatic and bloody lumbar puncture in children with acute lymphoblastic leukemia. JAMA. 2002 Oct;288(16):2001-7. [PubMed] [Google Scholar]

3. Devita VT, Chu E. A history of cancer chemotherapy. Cancer Res. 2008 Nov;68(21):8643-53. [PubMed] [Google Scholar]

4. Pui $\mathrm{CH}$, Mahmoud HH, Rivera GK, Hancock ML, Sandlund JT, Behm FG, Head DR, Relling MV, Ribeiro RC, Rubnitz JE, Kun LE, Evans WE. Early intensification of intrathecal chemotherapy virtually eliminates central nervous system relapse in children with acute lymphoblastic leukemia. Blood. 1998 Jul;92(2):411-5. [PubMed] [Google Scholar]

5. Pui CH. Childhood leukemias. N Engl J Med. 1995 Jun;332(24):1618-30. [PubMed] [Google Scholar]

6. Pinkel D, Hernandez K, Borella L, Holton C, Aur R, Samoy $G$, Pratt $C$. Drug dosage and remission duration in childhood lymphocytic leukemia. Cancer. 1971 Feb;27(2):247-56. [PubMed] [Google Scholar]

7. Mahmoud HH, Rivera GK, Hancock ML, Krance RA, Kun LE, Behm FG, Ribeiro RC, Sandlund JT, Crist WM, Pui $\mathrm{CH}$. Low leukocyte counts with blast cells in cerebrospinal fluid of children with newly diagnosed acute lymphoblastic leukemia. N Engl J Med. 1993 Jul;329(5):314-9. [PubMed] [Google Scholar]

8. Arora RS, Arora B. Acute leukemia in children: A review of the current Indian data. South Asian J Cancer. 2016 Jul-Sep;5(3):155-60. [PubMed] [Google Scholar]

9. Pui $\mathrm{CH}$, Relling MV, Downing JR. Acute lymphoblastic leukemia. N Engl J Med. 2004;350(15):1535-48. [PubMed] [Google Scholar]

10. Pui $\mathrm{CH}$, Cheng $\mathrm{C}$, Leung W, Rai SN, Rivera GK, Sandlund JT, Ribeiro RC, Relling MV, Kun LE, Evans WE, Hudson $M M$. Extended follow-up of long-term survivors of childhood acute lymphoblastic leukemia. N Engl J Med. 2003 Aug;349(7):640-9. [PubMed] [Google Scholar]

11. Grover G, Vinit PK, Thakur AK. Actuarial modelling of insurance premium for patients with acute lymphoblastic leukemia (ALL). J Appl Quant Methods. 2018;13(4). [Google Scholar]

12. Grover G, Thakur AK, Garg B. Cure fraction estimation for traumatic lumbar puncture in patients with acute lymphoblastic leukemia. Res Rev J Oncol Hematol. 2018;7(3):12-21.
13. Cancela CSP, Murao M, Viana MB, Oliveira BMD. Incidence and risk factors for central nervous system relapse in children and adolescents with acute lymphoblastic leukemia. Rev Bras Hematol Hemoter. 2012;34(6):436-41. [PubMed] [Google Scholar]

14. Chiang CL. A stochastic study of the life table and its applications: I. Probability distributions of the biometric functions. Biometrics. 1960;16(4):618-35. [Google Scholar]

15. Bowers NL, Gerber HU, Hickman JC, Jones DA, Nesbitt CJ. Actuarial mathematics. Transactions of the Faculty of Actuaries. 1987;41:91-4. [Google Scholar] 